\title{
EKSISTENSI LEMBAGA HISBAH DALAM SEJARAH (Analisis Terhadap Peran Muhtasib dalam Perdagangan)
}

\author{
Akhmad Mujahidin
}

\begin{abstract}
The Prophet Muhammad was the first muhtasib in the Muslim history. The first four caliphs of Islam carried out of functions of muhtasib themselves. The provincial governors during this era acted as muhtasibs on behalf of the caliph. With the expansion of the jurisdiction of the caliphate the office of the muhtasib also expanded and assumed and increased in sum of function. The institution of hisba remained in existence during the entire Muslim period of history, though it has been termed differently in various regions.
\end{abstract}

Key words: Hisbah, muhtasib and history.

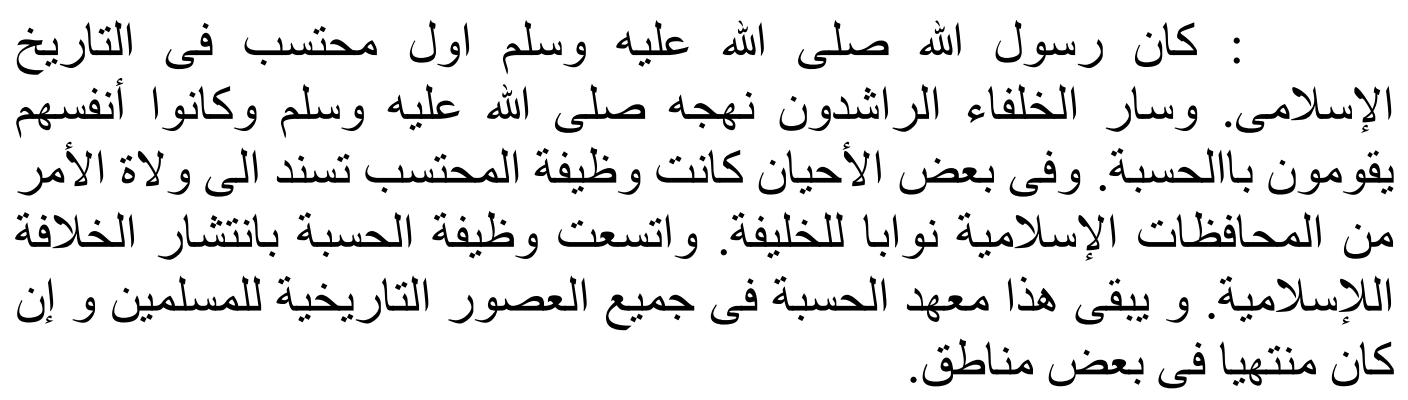

\section{Pendahuluan}

Dalam kajian sejarah dikenal dua teori. Pertama, teori siklus yaitu perubahan babakan sejarah yang dijelaskan sebagai gerak siklus (perulangan). Kedua, teori progress yaitu perubahan yang dijelaskan sebagai gerak maju (progress). ${ }^{1}$ Dalam teori siklus digambarkan bahwa kelangsungan segala sesuatu berjalan dalam suatu lingkaran untuk kemudian kembali lagi ke titik permulaan. Sementara teori progress menyatakan bahwa kejadian yang ada di muka bumi ini merupakan fenomena unik yang tidak mungkin terulang kembali.

Dalam kaitannya dengan lembaga hisbah, maka teori siklus nampaknya lebih tepat untuk diterapkan karena melihat fenomena kehidupan masyarakat muslim saat ini yang kesadaran beragamanya semakin kuat. Sebagai contoh, saat ini kaum muslimin telah mempunyai pilihan dalam menjalankan kegiatan di bidang keuangan. Jika sebelumnya hanya dikenal bank-bank umum dan asuransi yang terlepas dari kaidah-kaidah ajaran Islam, maka sejak lahirnya Bank Muamalat Indonesia, BPR Syari'ah, dan Asuransi Takaful, umat Islam dapat menjalankan kegiatan usahanya yang tidak hanya berdimensi duniawi tetapi juga berdimensi ukhrawi. Fenomena ini sudah dapat dipastikan menimbulkan semangat untuk menggali kembali lembaga-lembaga pada masa kejayaan Islam masa lalu untuk diterapkan kembali pada saat ini. Hisbah secara institusional dalam catatan sejarahnya mulai menghilang dari dunia Islam mulai abad $18 \mathrm{M}$, tetapi pelaksanaan kewenangannya tetap berjalan sampai saat ini yang tersebar di berbagai departemen. 
Al-Faruqi menyatakan bahwa teori siklus yang dikembangkan oleh Ibn Khaldun memiliki tiga fase yaitu lahir (born), berkembang (grow), dan mati (die). ${ }^{2}$ Dengan demikian teori ini menunjukkan bahwa gerak sejarah peradaban manusia itu berada dalam lingkaran era kebangkitan, keemasan, dan kehancuran. Masa depan selalu mengalami perubahan secara berkesinambungan dalam proses yang sama.

Hisbah merupakan salah satu bentuk peradaban umat Islam yang mengalami proses secara siklus. Masa kebangkitan dimulai sejak hijrahnya Rasulullah saw dari Mekkah ke Madinah (622 M) sampai dengan runtuhnya kekhalifahan Bani Umayyah $(750 \mathrm{M})$. Masa ini ditandai dengan embrio pelaksanaan wewenang hisbah yang terbatas pada aspek pengawasan terhadap praktek perdagangan di pasar dan moral masyarakat. Masa keemasan dimulai dari munculnya kekhalifahan Abbasiyyah (750 M) sampai tahun 1800-an. Masa ini ditandai dengan dilembagakannya hisbah dalam sistem ketatanegaraan yang disejajarkan dengan wilayat al-qad\{a dan wilayat al-mazalim. Dengan bertambah luasnya wilayah kekuasaan khalifah, maka kantor hisbah juga diperluas dan memegang sejumlah fungsi yang terus bertambah. Wewenang hisbah turut meluas seiring dengan meluasnya umat Islam di Barat seperti di Spanyol dan Afrika Utara. Bahkan hisbah menjadi bagian integral setelah terpecahnya kekhalifahan di Baghdad. Sedangkan, masa kehancuran hisbah dimulai dari masuknya kolonialisme Barat terhadap dunia Islam yaitu abad ke-18 sampai awal abad ke-20. Pada masa ini, nama lembaga hisbah sudah tidak ada di dunia Islam, namun kewenangannya didistribusikan ke departemen-departemen pemerintah. Pendistribusian ini dilakukan oleh kolonial dalam rangka menghilangkan fungsi-fungsi keagamaan hisbah, sehingga menjadi departemen yang sekuler. Ketiga masa tersebut dapat dilihat pada penjelasan berikut ini:

\section{Masa Kebangkitan (622-750 M).}

Al-Faruqi menyatakan bahwa hisbah merupakan lembaga khas Islam yang merupakan kontribusi besar bagi peradaban manusia. ${ }^{3}$ Tetapi beberapa orientalis mereduksi fakta tersebut dengan mengklaim bahwa hisbah, baik konsep maupun lembaganya, merupakan tiruan orang Arab muslim terhadap institusi Agronomos dalam tradisi Byzantium Romawi Timur. Klaim tersebut didasarkan pada wewenang Agronomos sebagai pengawas pasar yang mirip dengan salah satu wewenang muhtasib. ${ }^{4}$

Klaim para orientalis tersebut sulit untuk diterima mengingat beberapa hal penting berikut ini:

1. Lembaga hisbah dalam Islam dibentuk berdasarkan perintah amar ma'ruf nahi munkar yang terdapat dalam ayat al-Qur'an maupun Hadis Rasulullah saw. Oleh karena itu, lembaga hisbah dalam Islam lebih bersifat keagamaan daripada bersifat tradisi semata. Salah satu ayat yang menjadi landasan pelaksanaan hisbah adalah surat Ali Imran : 104, "Dan hendaklah ada diantara kamu segolongan umat yang menyeru kepada kebajikan, menyuruh kepada yang ma'ruf dan mencegah dari yang mungkar; merekalah orangorang yang beruntung". 5 'Abd al-Karim Zaydan menyatakan bahwa seluruh 
ayat al-Qur'an dan Hadis Rasulullah saw. yang berisi perintah tentang amar ma'ruf nahi munkar merupakan dasar hukum pelaksanaan hisbah dalam Islam. 6

2. Lembaga hisbah dalam Islam mempunyai wewenang yang lebih luas daripada sekedar pengawas pasar, yaitu menyangkut akidah, ibadah, muamalah, akhlak, dan ketertiban umum. Pengawasan terhadap pasar hanya merupakan salah satu wewenang saja. Dengan demikian tidak ada alasan yang kuat untuk menyamakan Agronomos dengan lembaga hisbah dalam Islam.

3. Berdasarkan fakta sejarah bahwa Rasulullah menunjuk Sa'id bin Sa'id al-'As sebagai muhtasib pasar Mekkah, setelah fath al-Makkah tahun $630 \mathrm{M}$, sedangkan pasukan Byzantium dikalahkan pasukan Islam dalam pertempuran di Yarmuk pada bulan Agustus $634 \mathrm{M}^{8}$ di bawah kepemimpinan Khalid bin Walid pada masa akhir jabatan Khalifah Abu Bakar dan awal Khalifah 'Umar bin al-Khattab, dan dalam pertempuran di Malazgird oleh pasukan Seljuk pada tahun 1071 M. ${ }^{9}$ Dengan demikian lembaga hisbah dibentuk pada awal Islam ketika belum ada kontak apapun dengan Byzantium. Jadi, bagaimana mungkin Islam akan meniru lembaga Agronomos Byzantium jika tidak ada kontak sama sekali dengan daerah tersebut.

Tugas hisbah ini, walaupun terlembaga secara resmi pada periode kemudian, namun pelaksanaannya telah dimulai dari masa yang paling awal yaitu masa Rasulullah saw, sesuai dengan tugasnya yaitu mengajak orang untuk melakukan kebaikan dan menjauhkan diri dari kemungkaran. Asal-usul lembaga $h\{$ isbah itu berawal ketika Rasulullah saw selalu melakukan pengawasan dan investigasi terhadap aktifitas yang dilakukan oleh para gubernur dan pejabatpejabat lainnya. Jika beliau mendapati salah seorang di antara mereka melakukan ketidakadilan maka beliau tidak segan-segan mengganti pejabat itu dengan yang lain. Selain itu beliau juga selalu melakukan pengawasan terhadap aktivitas pasar. ${ }^{10}$

Menurut Ibn Taymiyyah, Rasulullah saw melakukan inspeksi ke pasarpasar untuk mengecek harga dan mekanisme pasar. Abu Hurairah meriwayatkan bahwa Rasulullah saw sangat peduli dengan bahan makanan pokok. Jika harga padi-padian murah maka beliau pergi ke pasar untuk membuktikan apakah padi yang dijual itu basah atau kering dengan memasukkan tangan ke dalam onggokan padi tersebut. Beliau bertanya kepada penjual mengapa tidak meletakkan padi yang basah di atas sehingga orang mudah melihatnya. Lalu beliau bersabda bahwa orang yang menipu bukan golongan umatnya. ${ }^{11}$ Inspeksi pasar yang dilakukan Rasulullah saw ini tidak lain adalah upaya mencegah seseorang dari melakukan suatu tindakan yang bisa merugikan orang lain atau perbuatan yang tidak disukai Allah.

Untuk membantu melakukan pengawasan pasar, beliau menunjuk Sa'id bin Sa'id bin al-'As sebagai muhtasib pertama di pasar Mekkah"12 dan 'Umar bin al-Khattab sebagai muhtasib di pasar Madinah.13 Insiden ini secara jelas membuktikan bahwa lembaga hisbah itu telah ada pada masa Rasulullah, tetapi belum dibentuk secara resmi. Hal ini dapat dijadikan preseden bagi Khulafa' alRasyidin untuk melanjutkan keberadaan lembaga ini pada masa pemerintahan 
mereka. Pengawasan yang dilakukan oleh Rasulullah saw itu merupakan bagian penting dalam pelaksanaan amar ma'ruf nahi munkar agar dalam hubungan antar sesama manusia tidak ada yang dirugikan. Sehingga tercipta masyarakat yang damai dan tenteram dalam kehidupan beragama, berbangsa dan bernegara dengan semangat persaudaraan antar sesama manusia.

Pada masa al-Khulafa' al-Rashidun, lembaga hisbah terus berjalan sesuai dengan perkembangan masyarakat Islam yang terus menyebar ke berbagai kota besar seiring dengan perluasan wilayah kekuasaan daulah islamiyyah dari satu khalifah ke khalifah lainnya. Pada masa Abu Bakar (632-634 M), beliau sendiri yang menjadi muhtasib, seperti yang ditunjukkannya dengan tindakan memerangi orang-orang murtad, orang yang menafikan kewajiban membayar zakat dan orang yang mengaku menjadi nabi. Kemudian pada masa 'Umar bin al-Khattab (634-644 M), hisbah mendapat perhatian yang lebih serius. 'Umar sering mengadakan inspeksi ke pusat-pusat perdagangan dan memantau perkembangannya. Bahkan 'Umar terkenal sebagai khalifah yang rajin keluar pada malam hari untuk melihat keadaan rakyatnya. Salah satu kebijakan yang dilakukan 'Umar adalah mengangkat muhtasib tidak hanya dari kaum laki-laki, seperti Sa'id bin Yazid dan 'Abd Allah bin 'Utbah bin Mas'ud untuk pasar Madinah, tetapi juga dari kaum wanita, seperti Sayyidah al-Shifa' dan Samra' binti Nuhayk al-Asadiyyah di kota Madinah. ${ }^{14}$

Pada masa 'Umar, wewenang hisbah meliputi larangan terhadap unta yang kelebihan muatan di punggungnya, mengawasi penerapan akhlak yang mulia, mengawasi pelaksanaan hukum-hukum syari'ah, mengawasi peraturan yang berlaku di pasar-pasar, merubah perilaku masyarakat tanpa menimbulkan kekecewaan sehingga tidak menimbulkan tertundanya pelaksanaan hukum, memeriksa timbangan dan takaran untuk mencegah terjadinya kecurangan dan penipuan, memberi hukuman kepada para pelanggar syari'ah atau pelaku dosa, melarang penyerobotan terhadap hak-hak tetangga dan melarang bangunan orang non-muslim (ahl al-dhimmah) yang lebih tinggi dibandingkan bangunan kaum muslimin. ${ }^{15}$

Pada masa Khalifah 'Uthman bin 'Affan (644-656 M), muhtasib yang diangkatnya adalah al-Haris bin al-Hakam. Sedangkan pada masa Khalifah 'Ali bin Abi Thalib (656-661 M), beliau sendiri yang menjadi muhtasib dan mengadakan inspeksi ke pasar-pasar. Kemudian beliau juga mengangkat Samrah ibn Jamrah menjadi muhtasib di Kota Ahwaz. Tugas ini dilaksanakan sampai pada masa awal kekuasaan Daulah Bani Umayyah. ${ }^{16}$ Hal ini menunjukkan bahwa para al-Khulafa' al-Rasyidun telah menjadikan hisbah sebagai bagian penting dalam sistem pemerintahannya, sekaligus menjadikan dirinya sebagai muhtasib secara langsung selain petugas yang ditunjuknya.

Dengan adanya perintah al-Qur'an dan praktek yang dijalankan oleh Rasulullah itu, maka jelaslah bahwa sebuah negara terikat kewajiban untuk menjalankan dan mempraktekkan institusi hisbah ini, karena efektifitas kerja lembaga hisbah ini hanya bisa dicapai bila ada dukungan kekuatan politik. Hal ini bisa dilihat dari fakta sejarah, baik pada masa Rasulullah saw maupun pada masa khalifah sesudah beliau. Penentuan dan pengangkatan orang yang melakukan tugas hisbah dilakukan oleh negara. Kewajiban muhtasib adalah 
mengecek dan memeriksa skala dan harga barang dan mengawasi bisnis dagang apakah telah sesuai dengan cara-cara yang benar atau tidak. ${ }^{17}$

Sejarah memaparkan suatu bukti yang sangat jelas bahwa untuk melakukan pengawasan yang ketat ini negara Islam yang ada selalu memperhatikan dan mempraktekkan institusi hisbah ini. Hal ini menunjukkan bahwa dalam Islam kesejahteraan penduduk suatu negeri hanya bisa dicapai melalui perintah melaksanakan kebaikan dan mencegah kejahatan berdasarkan ketaatan kepada Allah dan Rasul-Nya. Fakta yang terjadi pada masa Rasulullah ini menunjukkan bahwa hisbah telah ditegakkan sejak berdirinya kota Madinah di bawah pimpinan Nabi Muhammad saw dan berlangsung sampai masa-masa berikutnya. Fakta ini semakin memperjelas bahwa penegakan hisbah tidak mungkin bisa dilakukan tanpa adanya intervensi pemerintah.

Fakta historis ini juga membuktikan bahwa sejak awal berdirinya negara Islam, perhatian yang sedemikian besar telah diberikan oleh pemerintah untuk melihat kondisi dagangan dan para pedagang apakah dalam melakukan perdagangan mereka telah menjalankan aturan seperti yang diajarkan Islam atau tidak. Di antara keempat khalifah, 'Umar bin al-Khattab ${ }^{18}$ adalah khalifah yang sangat menaruh perhatian dalam masalah ini.

Pada masa pemerintahan Bani Umayyah (661-750 M), pelaksanaan tugas peradilan tidak berbeda dengan masa al-khulafa' al- Rashidun. ${ }^{19}$ Tugas hisbah tersebut tidak begitu jelas pemisahannya dari tugas kepolisian biasa yang di antara wewenangnya adalah mengawasi pasar dari tindak penipuan. Namun dalam beberapa waktu ada satu badan yang disebut 'amil al-suq (petugas pasar) yang wewenangnya terbatas pada soal timbangan dan ukuran yang dipergunakan di pasar serta pelanggaran-pelanggaran kecil yang dapat diselesaikan dengan segera. Kemudian wewenangnya lebih luas lagi, mencakup hal-hal yang bisa mempertahankan moralitas Islam. ${ }^{20}$ Beberapa polisi pengaman juga diperintahkan untuk mengawasi masalah timbangan dan takaran ini. ${ }^{21}$ Kondisi ini bisa dimaklumi mengingat kekuasaan yang diperoleh Bani Umayyah adalah melalui "kudeta" terhadap kepemimpinan $\mathrm{H}$ \{asan bin 'Ali yang diangkat sebagai khalifah sepeninggal 'Ali bin Abi Talib, sehingga konsentrasi pemerintahan ini berkisar di sekitar kemapanan kekuasaan mereka.

\section{Masa Keemasan (750-1800 M)}

Pada masa pemerintahan Bani 'Abbas (750-1258 M), seperti halnya pada awal pemerintahan Bani Umayyah, juga tidak begitu jelas pemisahan antara tugas hisbah dengan kepolisian. Tugas hisbah selain dimasukkan ke dalam wewenang hakim biasa, juga ada hal-hal yang dimasukkan ke dalam wewenang kepolisian. Kepala kepolisian kota waktu itu disebut muhtasib yang bertugas mengawasi moral, pasar, ukuran, timbangan, mensahkan pembayaran hutang, mencegah terjadinya tindakan-tindakan terlarang, seperti perjudian, minuman keras dan sebagainya. ${ }^{22}$ Ini menunjukkan bahwa fungsi hisbah sangat ditentukan oleh waktu, tempat, kebiasaan, dan agenda politik penguasa yang bersangkutan. Hisbah menjadi salah satu lembaga peradilan secara resmi pada masa Khalifah alMahdi (775 M- 785 M).23 
Pada masa ini, hisbah merupakan lembaga yang secara khusus menangani dilaksanakannya perbuatan baik dan melarang perbuatan jahat. Tugas ini sebenarnya merupakan tugas yang dibebankan kepada kepada setiap muslim, namun diambil oleh negara dengan menunjuk pelaksananya yang disebut muhtasib. Kedudukannya melebihi qadi dalam hal menguji masalah-masalah yang berada dalam yurisdiksinya. Dia diberi bekal kekuasaan yang besar oleh khalifah sehingga berwibawa dan dihormati. Tugasnya terutama segala sesuatu yang berhubungan dengan Allah, manusia dan keduanya. Penjabarannya meliputi pengamanan pelaksanaan ibadah salat Jum'at, ketentraman kehidupan publik dan individu, keadilan dalam distribusi air, utang-piutang, mengatur tinggi-rendahnya bangunan perumahan penduduk, dan pengawasan terhadap perilaku pengacara dari penyuapan dalam pembelaan klien. ${ }^{24}$

Lembaga hisbah ini lebih berkembang pada pemerintahan 'Abd al-Rahman di Andalusia. Pemerintahan Bani Umayyah di Andalusia ini bertahan selama tiga abad yaitu antara tahun 756-1031 M. Jabatan hisbah pada masa ini pada dasarnya merupakan jabatan yang bersifat agamis, oleh karena itu, muhtasib bertugas dalam lingkup agama yang memerintahkan kebaikan dan mencegah kemungkaran. Muhtasib merupakan jabatan penting yang harus diemban oleh orang-orang yang memenuhi kualifikasi, seperti adil, jujur, berilmu, dan berwibawa. Muhtasib boleh mengangkat pembantu untuk mensukseskan tugasnya. Muhtasib berhak menyelidiki pelanggaran yang dilakukan masyarakat dan menjatuhkan hukuman yang pantas atau tindakan-tindakan korektif lainnya. Secara umum muhtasib memang tidak memiliki hak untuk menuntut hukuman, namun ia mempunyai kekuasaan untuk mengatasi berbagai pelanggaran yang berkaitan dengan penipuan dan kecurangan timbangan dan ukuran di pasar-pasar. Tugas lainnya adalah mengawasi orang-orang yang menunggak pembayaran hutang dan masalah-masalah lain yang tidak memerlukan pembuktian atau keputusan hukum di pengadilan. ${ }^{25}$

Dengan demikian, pada masa ini jabatan muhtasib berada di bawah jabatan hakim dan dapat mengangkat pembantu sesuai dengan kebutuhan dan kemampuan yang dimilikinya. Ketika kekuasaan berubah dan terpisah dari kekhalifahan, penguasa mengambil alih tugas umum masalah-masalah politik, maka muhtasib tetap eksis sebagai jabatan kebangsawanan dan mempunyai komunitas masyarakat tersendiri.

Pada masa Pemerintahan Fatimiyyah (893-1160 M), dalam bidang pemerintahan sama seperti pemerintahan pada masa Bani Umayyah di Spanyol dan Bani Abbas. Penanggulangan kejahatan dan pelaksanaan sanksi dilakukan oleh seorang kepala polisi yang disebut sahib al-shurtah. Sedangkan pengawasan pasar diserahkan kepada muh\{tasib. ${ }^{26}$ Pada masa ini muhtasib memiliki pembantu (nuwab) di beberapa daerah seperti Kairo, Mesir, dan kota-kota lain. Dia berkantor di Kairo, sementara para pembantunya berkeliling ke perusahaan dan pasar, memeriksa kualitas makanan dan daging, mengatur tempat kantor dan restoran, mengawasi kendaraan dan hewan agar tidak melebihi kapasitas angkutan yang dapat membahayakan penumpang dan hewan itu sendiri, mengawasi cara berpakaian masyarakat agar sesuai dengan tatakrama kesopanan, melarang para guru memukul murid yang masih kecil dan memeriksa ukuran, timbangan dan takaran di pasar agar terhindar dari 
kecurangan dan penipuan. ${ }^{27}$ Apabila muhtasib melihat seorang pedagang berbohong kepada pembeli, menjual dengan melebihi harga umum, maka ia segera menegur pedagang tersebut dari atas unta sambil memegang dan memukul lonceng serta mengelilingi kota dengan mengumumkan kepada masyarakat bahwa ada seorang pedagang yang telah melakukan kebohongan dan telah dihukum, setiap orang yang melakukan kebohongan pasti akan mendapat hukuman. ${ }^{28}$ Khan menyatakan bahwa lembaga hisbah tetap eksis sampai abad ke-18 walaupun dengan nama yang berbeda-beda. Di Baghdad bernama muhtasib, di Afrika Utara bernama sahib al-suq, di Turki bernama muhtasib aghasi, dan di India disebut kotwal. ${ }^{29}$

\section{Masa Kehancuran (1800-awal abad ke-20)}

Lembaga hisbah tetap bertahan sampai awal abad ke-18 di sebagian besar dunia Islam. Selama periode Dinasti Mamluk, institusi hisbah memegang peranan penting dalam menata kehidupan masyarakat terutama dalam pengumpulan zakat, pajak, dan kontrol terhadap ketertiban umum. Di Mesir, lembaga hisbah bertahan sampai masa pemerintahan Muhammad Ali (1805-1849 M). Di Marokko, lembaga seperti hisbah masih ditemukan sampai awal abad ke-20. Di Romawi Timur yang telah melakukan kontak dengan dunia Islam melalui Perang Salib, lembaga hisbah juga diadopsi dengan nama mathessep. ${ }^{30}$ Nama ini barangkali merupakan gubahan dari muhtasib dalam lembaga hisbah.

Pada masa pemerintahan Turki Usmani, tugas hisbah pada umumnya ditangani oleh peradilan biasa yang dibantu oleh kepolisian. Badan yang disebut terakhir ini termasuk wewenangnya mengawasi pasar dari tindakan-tindakan yang merusak moral. Sedangkan dalam hal-hal yang memerlukan pengesahan dan putusan dilimpahkan ke pengadilan. ${ }^{31}$

Jackson juga memberikan gambaran bahwa menjelang abad ke-19, jabatan muhtasib menghilang dari sebagian besar dunia Islam. Fungsinya yang banyak itu telah didistribusikan ke berbagai kewenangan modern dan sekuler. Kesultanan Uthmaniyah secara resmi menghapus jabatan muhtasib di Istambul pada tahun $1271 \mathrm{H} / 1893$ M. Di Persia nampaknya juga menghilang pada tahun tersebut. Di anak Benua India, jabatan muhtasib juga mengalami kemunduran sejak abad ke-16 dan muncul kembali dalam waktu yang singkat di bawah penguasa Mughal Aurangzeb. Dewasa ini masih terdapat sedikit saja sisa-sisa jabatan muhtasib abad pertengahan di bagian tertentu dunia Islam, misalnya, $r a^{\prime}$ is al-masalih al-iqtisadi (ketua kesejahteraan ekonomi) mungkin merupakan turunan dari muhtasib abad ke-19 yang karena kecenderungan campur tangannya digelari al-fuduli (orang yang mencampuri urusan orang lain), nizam al-tilbah (sistem derma) atau halaqat al-azabiyah (korps disiplin) ditemukan pada komunitas Ibadiyah di Aljazair mungkin merupakan turunan modern dari hisbah. ${ }^{32}$ Meskipun lembaga hisbah tetap berjalan selama periode awal sejarah Islam, namun kehadiran kolonialisme Barat telah memecah lembaga hisbah menjadi sejumlah departemen sekuler yang memandang muatan religiusnya tidak relevan atau menurunkannya ke posisi sekunder. ${ }^{33}$ 
Dengan demikian tugas hisbah dari awal Islam tetap berjalan dengan beberapa perkembangan dan perubahan dalam bentuk dan teknisnya. Jadi, berdasarkan fakta-fakta historis tersebut, wajar apabila Ambary menyatakan bahwa lembaga hisbah telah berkembang dalam sejarah umat Islam sampai hari ini, namun bentuknya berbeda antara satu negeri dengan negeri yang lain. Pernyataan Ambary sebagai berikut:

Dalam perkembangan sejarahnya, lembaga hisbah masih tetap ada di negeri-negeri Islam yang dikuasai Kerajaan Ottoman sampai hancurnya kerajaan tersebut pada tahun 1922. Dewasa ini negara Islam yang masih melestarikan lembaga hisbah antara lain adalah Arab Saudi, berdasarkan Surat Keputusan Kerajaan Arab Saudi tanggal 3-9-1396 H, dan Kerajaan Marokko, berdasarkan Undang-Undang Nomor 20/82 tanggal 21 Juni 1982. Sekalipun lembaga hisbah ini tidak ada lagi di beberapa negara Islam, termasuk Indonesia, tetapi tugas amar ma'ruf nahi munkar masih tetap berjalan. Wewenang lembaga hisbah ini terpencar di berbagai departemen. ${ }^{34}$

Pernyataan tersebut menunjukkan bahwa dengan melihat luasnya wewenang lembaga hisbah, maka pada saat ini dapat dipastikan tidak ada lembaga tunggal yang dapat dikomparasikan dengan lembaga hisbah. Oleh karena itu, wajar bila wewenang lembaga hisbah saat ini dilakukan oleh beberapa menteri dan departemen yang berbeda.

Dengan melihat fakta-fakta sejarah tersebut, dapat dinyatakan di sini bahwa amar ma'ruf nahi munkar merupakan salah satu dasar yang harus ditegakkan untuk tercapainya masyarakat yang tentram, damai, sejahtera dan aman dalam lindungan Allah swt. Islam memiliki konsep lembaga hisbah yang telah dilaksanakan sejak zaman Rasulullah saw sampai sekarang. Lembaga ini merupakan salah satu lembaga peradilan dalam Islam, selain qada dan mazalim, yang secara khusus dibentuk untuk mengawasi pasar dan moral masyarakat.

Pada zaman Rasulullah, embrio lembaga hisbah nampak ketika beliau melakukan inspeksi ke pasar Madinah untuk mengecek kualitas dagangan. Dalam inspeksi ini beliau menyatakan bahwa pedagang yang suka menipu dan curang bukan golongan umatnya. Keempat khalifah sesudah Rasulullah langsung bertindak sebagai muhtasib, tetapi yang melembagakan hisbah dalam sistem kekhalifahannya adalah 'Umar bin al-Khattab. Pada masa pemerintahan Bani Umayyah wewenang lembaga hisbah tidak berbeda dengan apa yang dilakukan pada masa al-Khulafa' al-Rasyidun, tetapi ada petugas khusus yang mengawasi pasar yang disebut 'amil al-suq. Pada masa pemerintahan 'Abbasiyyah, lembaga hisbah mendapatkan tempat yang lebih spesifik sebagai lembaga peradilan yang dibentuk pada masa al-Mahdi. Kepala kepolisian pada masa ini disebut muhtasib. Hisbah terus dikembangkan oleh Dinasti Fatimiyah di Mesir, Bani Umayyah di Andalusia. Namun harus disadari bahwa tatanan pemerintahan Islam saat ini tidak mesti harus sama dengan sistem pemerintahan Islam masa lalu, karena Rasulullah tidak pernah menentukan bentuk negara yang ideal bagi kaum muslimin. Selain itu, hal-hal yang menyangkut administrasi kenegaraan dapat berubah. Perubahan kondisi suatu masyarakat menyebabkan lembaga hisbah dapat berubah baik dari segi nama, kewenangan, dan pelaksanaannya dengan cara yang canggih dan profesional. Perubahan ini 
juga terjadi pada lembaga hisbah. Hal ini dibuktikan dengan nama-nama lain dari lembaga hisbah seperti 'amil al-suq pada masa Bani Umayyah, shurt\}at al-muh\{tasib pada masa Bani 'Abbasiyah, dan masa modern ini, di Marokko bernama ra' is almasalih al-Iqtisadiyyah (ketua kesejahteraan ekonomi), dan di Aljazair bernama niz\}am al-t\}ilbah (sistem derma) atau halaqat al-azabiyyah (korps disiplin). Tetapi intinya adalah menegakkan hukum Allah dengan melaksanakan amar ma'ruf nahi munkar.

\section{Penutup}

Dengan demikian, eksistensi lembaga hisbah dalam tatanan sistem pemerintahan, dalam hal ini kekuasaan yudikatif, merupakan bagian penting dari tugas dan wewenang lembaga peradilan dalam rangka pelaksanaan tugastugasnya agar lebih efektif dan efisien. Lembaga hisbah ini sangat diperlukan dalam rangka penciptaan masyarakat yang adil, makmur, tentram, dan sejahtera sebagaimana dicita-citakan oleh setiap warga negara dalam penyelenggaraan kehidupan berbangsa dan bernegara.

Dengan berkaca pada kejayaan pemerintahan Islam masa lampau yang mengalami kejayaan karena memiliki hisbah yang khusus menangani kasuskasus pelanggaran moral dalam berbagai aspek kehidupan serta didukung oleh muhtasib yang mempunyai integritas dan kualitas moral yang tinggi dan mulia maka pelembagaan hisbah merupakan suatu keniscayaan. Hisbah merupakan lembaga kontrol dalam masyarakat yang memiliki peranan penting, sebab dengan adanya lembaga ini, masyarakat akan semakin sadar dan berhati-hati dalam melakukan tindakan agar tidak terjerumus dalam suatu perbuatan yang bertentangan dengan nilai-nilai ajaran Islam. Memang telah ada lembaga peradilan (wilayat al-qada) yang menjadi garda terdepan dalam menegakkan hukum dan peraturan. Namun, pelanggaran-pelanggaran ringan yang tidak perlu adanya pembuktian, dan saksi-saksi, harus diatasi sesegera mungkin sebab kalau dibiarkan kehidupan masyarakat.

\section{Catatan Akhir:}

${ }^{1}$ G.W. Trompf, The Idea of Historical Recurrence in Western Thought From Antiquity to the Reformation (California: University of California Press, 1979), 61-62.

2 Al-Faruqi, Cultural, 313.

${ }^{3}$ Ibid., 156.

"Muhammad Akram Khan,"al-Hisba and the Islamic Economy", appendix dalam, Public Duties in Islam The Institution of the Hisba, trans. Mukhtar Holland (Nairobi Kenya: The Islamic Foundation, 1987), 139. Lihat juga, Cahen,"Hisba," 487. Dalam tulisan ini Lewis menyebut Agoranomos bukan Agronomos, tetapi keduanya memiliki arti yang sama yaitu pengawas pasar. Juga, G.E. Von Gruneboun, Classical Islam A History 600-1258 (London: George Allen and Unwin LTD, 1970), 101.

${ }^{5}$ Mujamma' Khadim al-Haramain asy-Syarifatain al-Malik Fahd li Thiba'at alMushhaf asy-Syarif, Al-Qur'an dan Terjemahnya (Medinah Munawwarah, 1971), 93.

${ }^{6}$ Zaydan, Usul, 174.

7 Zafir al-Qasimi, Nizam al-Hukm fi al-Shari'ah al-Islamiyyah al-Sultah al-Qada'iyyah (Beirut: Dar al-Nafa'is, 1987), 591. 
Al-Fikra: Jurnal Ilmiah Keislaman, Vol. 4, No. 2, Juli-Desember 2005

8 Hamdani Anwar,"Masa al-Khulafa' ar-Rasyodin," Ensiklopedia Tematis Dunia Islam, Jilid 2, ed. Taufik Abdullah et.al (Jakarta: Ichtiar Baru Van Hoeve, 2002), 47.

${ }^{9}$ Ibid.,"Kronika," Jilid 7, 3.

${ }^{10}$ Ibid., 246.

${ }_{11}$ Ibn Taymiyyah, al-Hisbah, 19. Lihat juga, Hamid Muhammad Abu Talib, alTanzim al-Qada'i al-Islami (Kairo: Matba'at al-Sa'adah, 1982), 22.

${ }^{12}$ Muhammad Mamduh al-'Arabi, Dawlat al-Rasul Salla Allah 'Alayhi wa Sallam fi alMadinah (Kairo: al-Hay'ah al-Misriyyah al-'Ammah li al-Kitab, 1988), 196. Lihat juga, alQasimi, Nizam al-Hukm, 591.

${ }^{13}$ Atiyyah Mustafa Mushrifah, al-Qad\}a' fi al-Islam (Beirut: Dar al-Sharq al-Awsat, 1966), 181.

14 Mushrifah, al-Qada', 181-182.

15 Hasan Ibrahim Hasan, Tarikh al-Islam al-Siyasi wa al-Dini wa al-Thaqafi wa alIjtima'i, juz I (Kairo: Maktabat al-Nahdah al-Misriyyah, 1979), 502.

${ }^{16}$ Abu Talib, al-Tanzim, 23.

${ }^{17}$ Cahen,"Hisba," 488.

${ }^{18}$ Para pakar sepakat bahwa walaupun para Khulafa' al-Rashidin melaksanakan tugas hisbah, namun yang melembagakannya sebagai institusi penting dalam pemerintahan adalah Khalifah 'Umar bin al-Khattab. Lihat, Muhammad Jalal Sharaf dan 'Ali 'Abd al-Mu'ti Muhammad, al-Fikr al-Siyasi fi al-Islam Shakhsiyyat wa Madhahib (Iskandariyah: Dar al-Jami' at al-Misriyyah, 1978), 16. Sharaf, Khasa'is al-Fikr al-Siyasi fi alIslam wa Ahamm Naz\}ariyyatih (Iskandariyyah: Dar al-Jami'at al-Misriyyah, 1975), 158. Ahmad Shalabi, al-Siyasah wa al-Iqtisadi fi al-Tafkir al-Islami (Kairo: Maktabat al-Nahdah al-Misriyyah, 1974), 171.

${ }^{19}$ Al-Sayyid 'Abd al-'Aziz Salim, Tarikh al-Dawlah al-'Arabiyyah Tarikh al-'Arab Mundhu 'Ashr al-Jahiliyyah Hatta Suqut al-Dawlah al-Umawiyyah (Beirut: Dar al-Nahdah al'Arabiyyah, 1987), 681.

${ }^{20}$ Tim Penulis IAIN Syarif Hidayatullah, Ensiklopedi Islam Indonesia (Jakarta: Djambatan, 1992), 325.

${ }^{21}$ Ambary,"Muhtasib," 61.

${ }^{22}$ Nagendra Kr. Singh, International Encyclopedia of Islamic Dynasties, vol 4 (New Delhi: Anmol Publications PVT. LTD, 2002), 91.

${ }^{23}$ Husayn Fawzi al-Najjar, al-Islam wa al-Siyasah Bahth fi Usul al-Nazariyyah alSiyasiyyah wa Nizam al-Hukm fi al-Islam (Kairo: Dar al-Ma'arif, 1975), 220. Muslehuddin, Judicial, 60-61. Ahmad, al-Hadarah, 112. Lihat juga, Tabanah, Ihya', juz II, 313. Dalam kitab ini, al-Ghazali memberi contoh tentang praktek lembaga hisbah pada masa al-Mahdi, alRashid, dan al-Ma'mun dari pemerintahan Dawlah 'Abbasiyyah.

${ }^{24}$ Qadri, Sebuah, 44.

${ }^{25}$ Hasan, Tarikh, Juz I, 502-503, Juz II, 300. Lihat juga, Anwar Ahmad Qadri, Sebuah Potret Teori dan Praktek Keadilan Dalam Sejarah Pemerintahan Muslim, ter. Edi S. Hariyadi (Yogyakarta: PLP2M, 1987), 33.

${ }^{26}$ Ibid., 54.

${ }^{27}$ Hasan, Tarikh al-Dawlah al-Fat jimiyyah fi al-Maghrib wa Misr wa Shuriyah wa Bilad al-'Arab (Kairo: Multazam al-Nashr wa al-Taba', 1958), 324. Lihat juga, Hasan, Tarikh alIslam, juz V, 375. Juga, Singh, International, vol 5, 439.

${ }^{28}$ Shalabi, Mawsu'at al-Tarikh al-Islami wa al-Hadarah al-Islamiyyah, juz VII (Kairo: Maktabat al-Nahdah al-Misriyyah, 1977), 56.

${ }^{29}$ Khan, al-Hisba, 137.

${ }^{30}$ Cahen,"Hisba," 488.

${ }^{31}$ Tim IAIN Syarif Hidayatullah, Ensiklopedi, 325-326. 
Al-Fikra: Jurnal Ilmiah Keislaman, Vol. 4, No. 2, Juli-Desember 2005

32 Jackson,"Muhtasib," 170. Pada masa Aurangzeb memang terdapat jabatan muhtasib yang secara khusus bertugas melakukan pengawasan terhadap tatakrama umum (a censor of public morals). Lihat, Singh, International, vol 20, 1349.

${ }^{33}$ Doi,"Hisbah," 114.

${ }^{34}$ Ambary, Suplemen , 62. 